\title{
On the Distributions of Ion/Neutral Molecule Clusters in Electrospray and Laser Spray- A Cluster Division Model for the Electrospray Process
}

\author{
Jan Sunner \\ Department of Chemistry and Biochemistry, Montana State University, Bozeman, Montana, USA \\ Iwona B. Beech \\ School of Pharmacy and Biomedical Sciences, University of Portsmouth, Portsmouth, United Kingdom
}

Kenzo Hiraoka

Clean Energy Research Center, University of Yamanashi, Kofu, Japan

\begin{abstract}
The clustering of a medium-sized, involatile, neutral molecule, octyl $\beta$-D-glucopyranoside (OG), with $\mathrm{Na}^{+}, \mathrm{Ca}^{2+}$, and $\mathrm{Yb}^{3+}\left(\mathrm{M}^{2+}\right)$ ions in electrospray (ESI) was investigated using laser spray (LSI). Extensive distributions of $\left[\left(\mathrm{M}^{\mathrm{z}}\right)_{\mathrm{i}}(\mathrm{OG})_{\mathrm{a}}\right]^{n+}$-clusters, extending beyond $50 \mathrm{kDa}$, were observed. The distributions were highly stable and reproducible and changed only marginally when concentrations of electrolyte or neutral compound were varied by orders of magnitude. Compared with ESI, laser spray yielded superior intensities, particularly of the larger clusters. The cluster distributions demonstrated a range of remarkable features. In particular, the $\mathrm{Yb}^{3+} / \mathrm{OG}$ cluster distribution was unusual. For example, no clusters with 35-52 or with 110-116 OG molecules were observed. The distribution pattern revealed that the clusters were formed as a result of cluster dissociations, such as $\left[\left(\mathrm{Yb}^{3+}\right)_{3}(\mathrm{OG})_{\sim 110} \mathrm{~W}\right]^{9+} \rightarrow\left[\left(\mathrm{Yb}^{3+}\right)_{2}(\mathrm{OG})_{\sim 90} \mathrm{~W}\right]^{6+}+\left[\left(\mathrm{Yb}^{3+}\right)_{1}(\mathrm{OG})_{\sim 20} \mathrm{~W}\right]^{3+}$, where $\mathrm{W}$ represents the water content at the time of dissociation. Based on this study, a cluster division model for electrospray of aqueous solutions of strongly solvated ions is proposed: the Rayleigh droplet disintegration process, which is well-established for the initial stages of electrospray, maintains its general character as it proceeds through a final regime of multiply charged cluster dissociations to the singly and multiply charged ions in mass spectrometry. In the dissociation of multiply charged clusters, the size of each daughter cluster is roughly proportional to the square of the cluster charge. Observed cluster distributions are consistent with a mixture of symmetric and asymmetric cluster dissociations. (J Am Soc Mass Spectrom 2006, 17, 151-162) (c) 2006 American Society for Mass Spectrometry
\end{abstract}

$\mathrm{F}$ ollowing the discovery of electrospray $[1,2]$, the mechanism of ion formation became a subject of intense investigations and debate. Under conditions when a well-formed Taylor cone forms at the end of the electrospray capillary, a thin jet is ejected from the tip of the cone. Charged droplets are produced as this jet disintegrates. In many devices, a high-velocity gas stream is used to further promote droplet formation [3]. In the latter case the size and charge of the initially formed droplets are also determined by the aerodynamic spray conditions.

Published online January 19, 2006

Address reprint requests to Dr. J. Sunner, Department of Chemistry and Biochemistry, Montana State University, P.O. Box 173400, Bozeman, MT 59717-3400, USA. E-mail: sunner@chemistry.montana.edu
The maximum charge that a droplet can theoretically carry is given by the Rayleigh equation [4],

$$
\mathrm{Z}_{\mathrm{RS}}=\left(\gamma \varepsilon_{\mathrm{o}} \mathrm{R}^{3}\right)^{0.5} \times 8 \pi / \mathrm{e}
$$

where $Z_{R S}$ is the maximum number of elementary charges on the droplet, $\mathrm{R}$ is the droplet radius, $\gamma$ is the surface tension, $\varepsilon_{\mathrm{o}}$ is the electric permeability of vacuum, and e is the elementary charge. Charged droplets undergo a sequence of disintegrations as evaporation of (neutral) volatile solvent molecules cause droplets to approach their Rayleigh stability limit.

It has been reported that water droplet fission occurs at $\sim 90 \%$ of the Rayleigh limit and that, immediately after fission, the parent droplets are at about $70 \%$ of the limit 
[5]. The detailed mechanisms and outcomes of such disintegrations are subjects of ongoing research $[5,6]$.

The ejection of small "daughter" droplets from a Taylor-cone-like protrusion formed on a larger charged droplet, i.e., droplet disintegration, has been documented photographically [7]. Relative to their mass, the daughter droplets carry a disproportionately large fraction of the parent droplet charge. In modeling the droplet disintegration process, it has been assumed that $\sim 20$ smaller droplets are produced and that together they carry $2 \%$ of the mass and $15 \%$ of the charge of the parent droplet [7-9]. Although these values may serve as a rough estimate, they should be treated cautiously. The type of solvent used in the original study [7] was heptane doped with an antistatic fuel additive and thus very different from the polar solvents typically used for electrospray. It has also been reported that the charge loss in water is in the range of 20 to $40 \%$ [5].

Experimental observations have been limited to droplets with radii larger than about $4 \mu \mathrm{m}$ [5]. It is worth noting that a $4 \mu \mathrm{m}$ radius droplet has approximately ten orders of magnitude larger mass and five orders of magnitude higher charge than the ions observed in mass spectrometry. The number of consecutive disintegrations ("droplet generations") required for such a droplet to generate a singly charged ion might range from about 3 to more than 10, depending on the percentage charge loss and number of daughter droplets formed throughout the process. In each droplet disintegration event not only mass and net charge but also all chemical species present in the parent droplet will be unequally distributed between the produced droplets. The extent to which a particular chemical species will be enriched or depleted in daughter droplets will depend on a multitude of factors, including analyte mass, charge, acid/base properties, and surface activity [10, 11]. It is also expected that there should be a significant statistical variability in the outcomes, especially for the smallest droplets. Hence, after several consecutive droplet disintegrations, large variations in droplet charge, size, and composition are likely. The ions observed in mass spectra should be produced from a subset of the disperse droplet population. Other large droplets become dead-ends, unable to generate ions. Clearly, droplet disintegration mechanisms are of paramount importance to the outcome of the electrospray process. Therefore, providing a detailed description of the cascade of droplet disintegrations will be crucial to achieve a full understanding of critical but yet unsolved issues in electrospray mass spectrometry such as (1) the relationship between protein folding and protein charge distributions and (2) full understanding of the behavior and detection of non-covalent complexes.

\section{The IEM and CRM Models}

The discussion of the ESI mechanism has centered on two "competing" theories, namely the ion evaporation model (IEM) proposed by Iribarne and Thomson [12-
14] and the charged residue model (CRM) favored by Dole et al. [15].

The CRM model has been described [16] as a sequence of Rayleigh instability-drive decompositions ("Coulomb explosions") with intervening periods of solvent evaporation that produces ultimate droplets, each of which contains only one molecule of solute. That molecule becomes a free gas-phase ion by retaining some of its droplet's charge as the last of its solvent evaporates. It is commonly stated that large ions, in particular multiply charged proteins, are formed by this mechanism.

According to the IEM, the process of ion formation starts with a sequence of droplet disintegrations. However, before becoming small enough to contain a single solute particle, the electric field at the surface of the droplets becomes large enough for individual solute ions to detach from the droplet surface, i.e., "ionevaporation" [12-14]. Much discussion on IEM has centered on the rate of the process, i.e., on the nature and energy of the transition-state $[9,17]$.

A widely accepted model of electrospray emerged as a result of extensive studies by Gamero-Castano and de la Mora [17-21]. In these landmark investigations, solutions of organic salts, $\mathrm{A}^{+} \mathrm{B}^{-}$in the organic solvents, formamide, and propanol, were electrosprayed and mobilities of the formed charged species measured. Of particular importance was the ability to neutralize multiply charged species to produce singly charged cluster ions for mobility measurements. Mobility peaks could be identified with $\left(\mathrm{A}^{+}\right)_{\mathrm{z}}\left(\mathrm{A}^{+} \mathrm{B}^{-}\right)_{\mathrm{n}}$ clusters and with large charged residues. Conducting such measurements, the authors achieved an unprecedented and detailed picture of the ESI process. It was found that each charge state, $z$, had only a limited range of aggregation $n$, with $\mathrm{n}_{\max }(\mathrm{z}-1) \approx \mathrm{n}_{\min }(\mathrm{z})$. Thus, nonoverlapping abundance regions were formed when charges were plotted against cluster size $[19,20]$. In addition, the total abundance of such clusters displayed a strong modulation. It was also found that dried, charged residues had a charge that was close to the Rayleigh limit for a solvent droplet of the same diameter.

In separate experiments, Gamero-Castano and de la Mora [20] produced very small initial droplets in an effort to suppress Coulomb explosions. It was found that only singly charged ions, $\left(\mathrm{A}^{+}\right)\left(\mathrm{A}^{+} \mathrm{B}^{-}\right)_{\mathrm{n}}, \mathrm{n}$ $=1-5$, were formed. Their study concluded that ion evaporation produced only such small, singly charged ions, and that all multiply charged ions were formed by the charged residue mechanism. Furthermore, they stated that the initial cascade of droplet disintegrations in electrospray was followed by a sequence of ion evaporation events in the final phase. Ion evaporation occurs from droplets with radii smaller than a critical value, which may range from a few $\mathrm{nm}$ to up to $20 \mathrm{~nm}$. The transition between the two mechanisms was described as being sharply defined [20]. This model appeared to settle the controversy between IEM and CRM as it proposed that 
small ions, e.g., $\mathrm{Na}^{+}$, are formed by IEM, while large ions such as proteins are formed by CRM [9]. Here, this model is referred to as the "Coulomb explosions to ion evaporation transition" model.

\section{Laser Spray Ionization (LSI)}

In laser spray, the tip of an electrospray capillary is irradiated with a continuous $\mathrm{CO}_{2}$ laser beam [22]. In our previous work it has been found that applying a modified laser spray method that employs a relatively low laser irradiance level (a laser power of $\sim 2 \mathrm{~W}$ and a focal spot size $\sim 0.3 \mathrm{~mm}$ ) resulted in a quiescent and smooth vaporization of aqueous solutions [23]. This "evaporation-mode" laser spray method yield the best results with laser-irradiated electrospray, producing higher and more stable signals for low concentrations of analytes. The present investigation benefited greatly from using "evaporation mode" laser spray. While spectra obtained with (LSI) or without (ESI) laser irradiation were essentially identical, laser spray ionization generally yielded higher intensities and thus better data.

\section{Clusters in ESI}

Electrospray is remarkable for its ability to produce multiply charged ions of large molecules [24-26]. Likewise, large, multiply charged clusters with more than one molecule per charge are generated, and this has been referred to as "fractional charging" [27]. The formation of such clusters, as a function of experimental variables, has been a subject of numerous studies [2834]. Investigations of micelle-forming systems represent a particular category of cluster investigations [35-40]. It has been found that clusters in these systems are unusually large, and it has been proposed that such clusters are formed directly from preexisting, noncovalently bonded supramolecular assemblies [35, 41].

The formation of clusters in any ionization method in mass spectrometry is very sensitive to the nature and evolution of the molecular environment during the ionization event. Therefore, in approaching the problem of the mechanism of an ionization method, the study of clusters offers an excellent model system [42-45]. This communication reports the use of neutral, involatile molecules such as octyl $\beta$-glucopyranoside (OG), Scheme 1, and sucrose to probe ion cluster formation in ESI and LSI to elucidate the mechanism of the final stages of electrospray process.

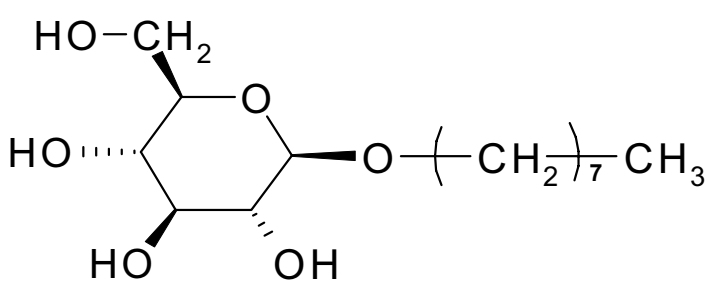

Scheme 1. Structure of octyl $\beta$-glucopyranoside (OG).

\section{Experimental}

The experiments were performed in a home-build electrospray setup, with an option to run laser spray. The general experimental procedures were similar to those described previously [23] and in references therein. Briefly, a sample solution was delivered to a stainless steel capillary (i.d.: $0.1 \mathrm{~mm}$, o.d.: $0.2 \mathrm{~mm}$ ) at atmospheric pressure by a syringe pump (Harvard Apparatus, type 11 Plus, Holliston, MA). The flow rate of the solution was $5 \mu \mathrm{L} / \mathrm{min}$. Nebulizer gas, $\mathrm{N}_{2}$, effusing from a concentric stainless steel tube (i.d.: $0.7 \mathrm{~mm}$ ) reduces the angular divergence of the plume and entrains the mist and gas in a confined gas stream going towards the sampling orifice. The flow rate of the $\mathrm{N}_{2}$ nebulizer gas was about $0.5 \mathrm{~L} / \mathrm{min}$. The needle voltage was $2.7 \mathrm{kV}$. The ions, charged clusters, and droplets formed in the spray process were sampled into the vacuum through a $0.40 \mathrm{~mm}$ diameter orifice of a sampling cone protruding out of an interface plate. The ESI capillary was positioned parallel to the interface plate. The distance between the ESI capillary tip and the centerline through the sampling cone was $15 \mathrm{~mm}$.

The ions were mass analyzed in an orthogonal time-of-flight mass spectrometer (Accu-TOF, JEOL, Musashino, Tokyo) over the $\mathrm{m} / \mathrm{z}$ range of 100 to 10,000 . The voltage difference between the orifice and the skimmer was kept at $40 \mathrm{~V}$ to suppress the collisioninduced dissociation of ions sampled into the first vacuum chamber.

A Synrad Firestar V20, model FSV20SFB, laser (Synrad, Mukilteo, WA) $20 \mathrm{~W}$ infrared laser $(10.6 \mu \mathrm{m})$ was used in laser spray mode. The tip of the stainless steel capillary was irradiated axially, from the opposite side of the capillary, by a laser beam focused to a $\approx 0.3 \mathrm{~mm}$ diameter spot with the laser power of up to $2.0 \mathrm{~W}$. The beam was focused by a $200 \mathrm{~mm}$ focal length ZnSe lens. The power of the Synrad laser was varied by pulsewidth modulation at a repetition frequency of $5 \mathrm{kHz}$. Essentially, the laser was turned on and off every 200 $\mu \mathrm{s}$. Thus, the optical waveform consisted of a series of pulses. However, the rise and fall time constant was about $100 \mu \mathrm{s}$, and for this reason the maximum instantaneous laser power was only about double the average power. At $2 \mathrm{~W}$, the average laser power density was calculated to be $3 \times 10^{3} \mathrm{~W} / \mathrm{cm}^{2}$, with a maximum of about $6 \times 10^{3} \mathrm{~W} / \mathrm{cm}^{2}$. Laser power levels higher than 2 $\mathrm{W}$ were used only for limited time periods, or the tip of the stainless steel capillary would melt and change shape. The laser spray was monitored by a CCD camera (Toshiba, type IK, $52 \mathrm{~V}$, Toshiba Teli, Tokyo, Japan), and the image was displayed on a CCD monitor with $200 \times$ magnification.

All chemicals were of analytical grade and obtained commercially from (Sigma, Tokyo, Japan). The water solvent was prepared by purification of the distilled water with ion-exchange resins (Millipore, Simpli Lab., Tokyo, Japan). 

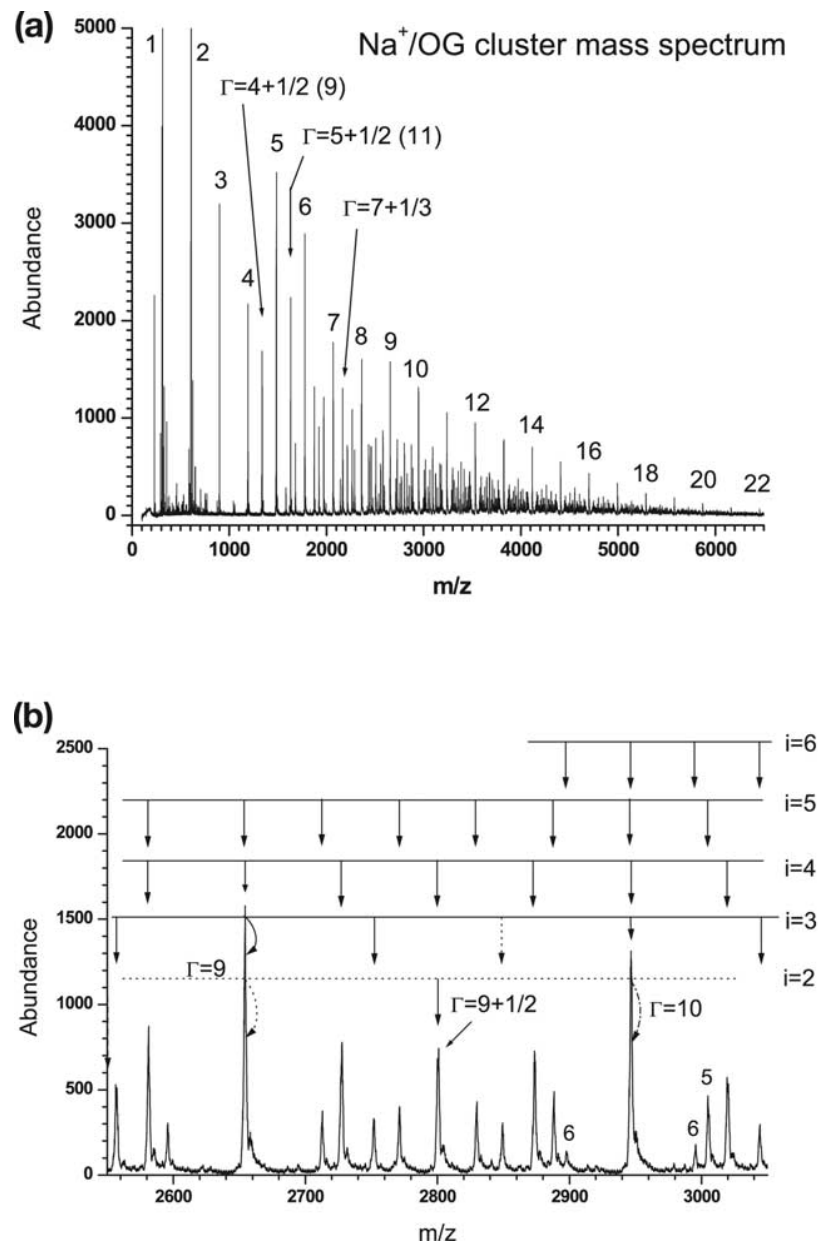

Figure 1. (a) Electrospray mass spectrum, obtained using laser spray, of a $1.0 \times 10^{-4} \mathrm{M} \mathrm{NaI}$ and $50 \mathrm{mM}$ OG aqueous solution, showing a wide distribution of $\left[\mathrm{Na}_{\mathrm{i}}^{+}(\mathrm{OG})_{\mathrm{a}}\right]^{n+}$ clusters. The major ("cardinal") sequence is nominally due to $\mathrm{Na}^{+}(\mathrm{OG})_{\mathrm{a}}$ clusters and is denoted with the cardinal number, $\Gamma(=\mathrm{a} / \mathrm{i})$. However, above $\Gamma=6$ these are primarily due to clusters with multiple $\mathrm{Na}^{+}$ions with the same $\mathrm{m} / \mathrm{z}$ ratios. A second sequence of doubly charged ions has half integer cardinal numbers. The peak denoted " $\Gamma=$ $7^{1} / 3^{\prime \prime}$ belongs to the series of triply charged clusters. (b) Detail of the cluster spectrum in Figure 1a indicating series with $i=2$ to 6 .

\section{Results}

\section{Example of Spectra}

The mass spectrum in Figure 1a, obtained with $50 \mathrm{mM}$ OG and $1.0 \times 10^{-4} \mathrm{M} \mathrm{NaI}$ in water, is representative of mass spectra collected during this investigation. The spectrum is also similar to previously recorded spectra for surfactants [35-37] and will here be used to illustrate the spectral analysis. The intensities of bare metal ions were insignificant. The poor sensitivity to these ions in ESI is widely accepted and, most likely attributable to low sensitivity in the ionization process.

Series of peaks seen in Figure 1a can all be attributed to $\left[\mathrm{Na}_{\mathrm{i}}^{+}(\mathrm{OG})_{\mathrm{a}}\right]^{n+}$ clusters with varying values of $\mathrm{i}$ and $\mathrm{a}$, as detailed below. For brevity, these clusters are referred to as $[i, a]$. For multiply charged ions, the number of ions in a cluster (i) is numerically different from the number of charges. Therefore, " $\mathrm{n}$ " is used for the charge state. No iodide-containing clusters could be identified. The most prominent series of peaks in the spectrum in Figure 1a are denoted with "cardinal" numbers $\Gamma$ (where $\Gamma=\mathrm{a} / \mathrm{i}$ ) from 1 to 22 . This is analogous to the " $\mathrm{n} / \mathrm{z}$ parameter" of Rodriguez and Yost for bile acid clusters [39]. The main sequence peaks are separated by the OG molecule mass of $292.3 \mathrm{Da}$, and extend beyond $m / z=7000$. The $m / z$ ratios for this series of peaks are those expected for OG clusters charged with a single sodium ion, $\mathrm{Na}^{+}(\mathrm{OG})_{a}, \mathrm{a}=1$ to 22 . This is indeed the correct identification at low $\mathrm{m} / \mathrm{z}$. However, for values of $\Gamma>4$, these peaks are mainly due to overlapping series of multiply charged $\left[\mathrm{Na}_{\mathrm{i}}^{+}(\mathrm{OG})_{\mathrm{a}}\right]^{\mathrm{i}}$ clusters, as explained below.

Peaks belonging to a second series appear halfway between successive peaks in the main $i=1$ sequence. Selected peaks are denoted by half integer cardinal numbers. Despite its lower abundance, this series is also seen to extend to approximately $\mathrm{m} / \mathrm{z}=7000$. The lowest mass peak in this series is found between the $\Gamma=3$ and $\Gamma=4$ peaks and is assigned to the $[2,7]$ cluster, i.e., $\left[\mathrm{Na}_{2}^{+}(\mathrm{OG})_{7}\right]^{2+}$ with $\Gamma=3 \frac{1}{2}$. The next larger cluster in this sequence, $[2,8]$, has the same $m / z$ ratio as $[1,4]$. Inspection of the isotope peak distribution showed that the $[1,4]$ and $[2,8]$ clusters contribute approximately equally to the observed abundance. The abundance of the $\Gamma=4 \frac{1}{2}$ peak is due solely to the $[2,9]$ cluster. However, both the $[2,10]$ and $[1,5]$ clusters contribute to the abundance of the $\Gamma=5$ cardinal peak, with $[2,10]$ being the more abundant. The abundance of the $[2, \mathrm{a}]$ series of clusters is seen to peak at $\Gamma=5 \frac{1}{2}$. At higher values of $\mathrm{a}$, interferences from clusters with more than two charges must be considered. For example, the abundance of the $\Gamma=7 \frac{1}{2}$ peak contains a contribution not only from [2,15] but also from the quadruply charged $[4,30]$ cluster.

The lowest mass, triply charged cluster appears as a small peak just above the $\Gamma=5$ cardinal peak at $\Gamma=5^{1} / 3$. This is the $[3,16],\left[\mathrm{Na}_{3}^{+}(\mathrm{OG})_{16}\right]^{3+}$ cluster with a mass of $4745 \mathrm{Da}$. Similarly, the lowest mass quadruply charged cluster is $[4,27]$ found at $\Gamma=6 \%$. At higher mass, sequences with five to ten $\mathrm{Na}^{+}$ions were identified.

An expanded view of the spectrum in Figure 1a, mainly between the $\Gamma=9$ and 10 cardinal sequence peaks, is depicted in Figure 1b. Calculated $\mathrm{m} / \mathrm{z}$ ratios for $i=2$ to 6 clusters sequence peaks are indicated at the top, facilitating identification of experimentally obtained peaks. It is seen that sequences $\mathrm{i}=3,4$, and 5 dominate in the $\Gamma=9$ to 10 region, and that the $i=6$ sequence appears at and above $\Gamma=9^{5} / 6$. This peak is due to the $\left[\mathrm{Na}_{6}^{+}(\mathrm{OG})_{59}\right]^{6+}$ clusters at $m / z=2898$.

It is apparent in Figure $1 \mathrm{~b}$ that the two cardinal peaks, $\Gamma=9$ and 10 , carry contributions from all series present in this $\mathrm{m} / \mathrm{z}$ range. Indeed, the abundances of the two peaks are fully accounted for by contributions from series $i=3$ to 6 (within the uncertainty of the measurements). Similarly, the peaks at half-integral $\Gamma$ values include contributions from all series with even i-values. 
In the case of the $\Gamma=91 / 2$ peak in Figure $1 b$, it is seen that this peak is no more intense than the neighboring peaks in series $i=4$, i.e., at $\Gamma=91 / 4$ and $93 / 4$. The contributions from series $i=6$ and higher are negligible. While it is not possible to conclude that abundance contribution from the $[2,19]$ cluster is nil, it is certainly quite low, and essentially the only contribution to the $\Gamma=91 / 2$ peak in Figure $1 \mathrm{~b}$ is due to the $\left[\mathrm{Na}_{4}^{+}(\mathrm{OG})_{38}\right]^{4+}$ cluster.

\section{$\mathrm{Na}^{+} / \mathrm{OG}$ Cluster Abundances}

The abundances of $[i, a]$ clusters were determined from mass spectra as described above. When the peaks from two of more sequences overlapped, a best effort was made to determine the respective contributions. Above $m / z \sim 2000$, the isotope peaks could not be resolved, and the relative contributions of the different series were obtained by interpolation between the next higher and next lower peaks in respective series.

It was found that electrospray and laser-assisted electrospray (laser spray) yielded very similar cluster distributions. The main differences were that the overall abundances of the clusters were substantially higher with laser spray. In particular, using LSI it was possible to extend the measurements to larger clusters, higher $\mathrm{m} / \mathrm{z}$ values, and lower concentrations. This was significant, as the extension of the cluster peaks series to the highest possible mass was essential to this study. As seen in Figure 1a, the cluster peaks gradually disappeared in the spectrum noise at $m / z=6000$ to 7000 . At high $\mathrm{m} / \mathrm{z}$, the identification of cluster peaks and the measurement of their abundances became increasingly uncertain. The highest mass cluster identified in the spectrum in Figure 1a was $\left[\mathrm{Na}_{9}^{+}(\mathrm{OG})_{188}\right]^{9+}$, at $\Gamma=$ $20^{8} / 9$, and with a mass of over $50 \mathrm{kDa}$ and the highest charge cluster had ten $\mathrm{Na}^{+}$ions.

The analysis described above yielded abundances for over 400 clusters with different combinations of $i$ and a. The abundances for those 65 clusters that have 50 or fewer OG molecules are listed in Table 1. This table is useful for understanding further analysis of the cluster abundance data.

The abundances for clusters with a given number of $\mathrm{Na}^{+}$ions were summed, i.e., the abundances in each column in the Table were added. This procedure is justified since the transmission efficiency in the instrument used in this study has only a weak dependence on mass for $\mathrm{m} / \mathrm{z}$ values above 100 . The result of these calculations is shown in Figure 2. It can be seen that there is a sharp decline in abundance from $i=1$ to $i=$ 2 . The abundance then remains relatively constant and starts a gradual decrease for i larger than 4 .

By adding the abundance values for each row in Table 1, one obtains the total abundance of all clusters with a given number of OG molecules, $\mathrm{I}_{\mathrm{a}}=\Sigma \mathrm{I}_{\mathrm{i}, \mathrm{a}}$. As already discussed, the number of different clusters for any given "a" is small and ranges from one at low a-values to three at high a-values. The result is plotted in Figure 3a, which shows $I_{a}$ as a function of the number
Table 1. Abundances of $\left[\left(\mathrm{Na}^{+}\right)_{\mathrm{i}}(\mathrm{OG})_{\mathrm{a}}\right]^{\mathrm{n}+}$ clusters, with 50 or fewer OG molecules obtained from the spectrum in Figure 1. The total number of different cluster peaks was more than 400

\begin{tabular}{|c|c|c|c|c|c|}
\hline \multirow[b]{2}{*}{$\mathrm{m}=\# \mathrm{OG}$} & \multicolumn{5}{|c|}{$\#$ of $\mathrm{Na}^{+}$ions } \\
\hline & 1 & 2 & 3 & 4 & 5 \\
\hline 1 & 8876 & & & & \\
\hline 2 & 22840 & & & & \\
\hline 3 & 3189 & & & & \\
\hline 4 & 1300 & & & & \\
\hline 5 & 1000 & & & & \\
\hline 6 & 347 & & & & \\
\hline 7 & & 40 & & & \\
\hline 8 & & 1200 & & & \\
\hline 9 & & 1642 & & & \\
\hline 10 & & 2800 & & & \\
\hline 11 & & 2242 & & & \\
\hline 12 & & 2300 & & & \\
\hline 13 & & 889 & & & \\
\hline 14 & & 283 & & & \\
\hline 15 & & 142 & & & \\
\hline 16 & & & 253 & & \\
\hline 17 & & & 726 & & \\
\hline 18 & & & 979 & & \\
\hline 19 & & & 1315 & & \\
\hline 20 & & & 1204 & & \\
\hline 21 & & & 1274 & & \\
\hline 22 & & & 1288 & & \\
\hline 23 & & & 1048 & & \\
\hline 24 & & & 892 & & \\
\hline 25 & & & 677 & & \\
\hline 26 & & & 778 & & \\
\hline 27 & & & 375 & 74 & \\
\hline 28 & & & 303 & 170 & \\
\hline 29 & & & 276 & 340 & \\
\hline 30 & & & 161 & 566 & \\
\hline 31 & & & 46 & 637 & \\
\hline 32 & & & & 680 & \\
\hline 33 & & & & 706 & \\
\hline 34 & & & & 764 & \\
\hline 35 & & & & 865 & \\
\hline 36 & & & & 798 & \\
\hline 37 & & & & 731 & \\
\hline 38 & & & & 717 & \\
\hline 39 & & & & 676 & \\
\hline 40 & & & & 594 & \\
\hline 41 & & & & 512 & 72 \\
\hline 42 & & & & 495 & 144 \\
\hline 43 & & & & 478 & 187 \\
\hline 44 & & & & 386 & 259 \\
\hline 45 & & & & 294 & 302 \\
\hline 46 & & & & 266 & 345 \\
\hline 47 & & & & 257 & 372 \\
\hline 48 & & & & 206 & 400 \\
\hline 49 & & & & 155 & 428 \\
\hline 50 & & & & 142 & 424 \\
\hline
\end{tabular}

of OG molecules. It is seen that the cluster abundances oscillate strongly, especially at lower a-values. As an example, the total abundance of clusters with less than 5 or with more than 8 OG molecules is much higher than with 6 or 7 OG molecules. This oscillating pattern is very similar to the one reported by Gamero-Castano and de la Mora for organic cluster ions [19]. A compar- 


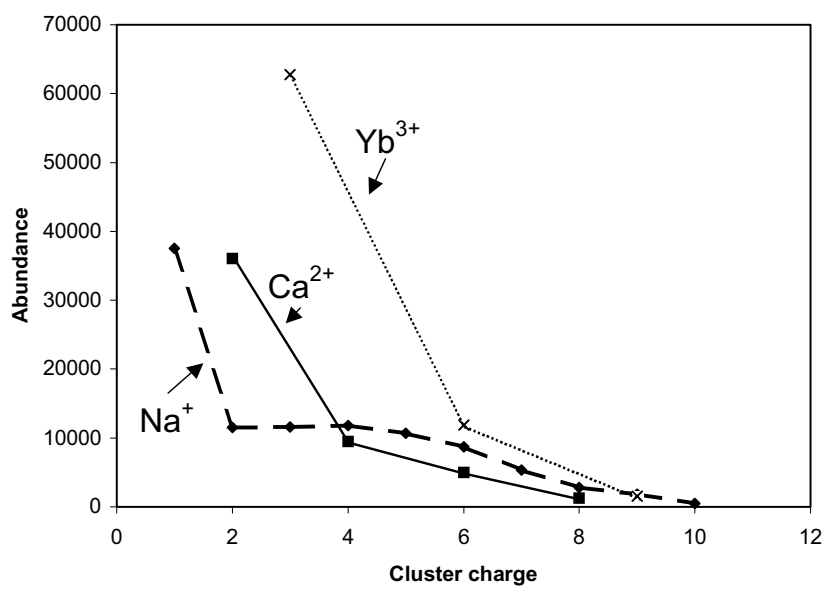

Figure 2. The total abundance of $\left[\left(\mathrm{M}^{\mathrm{z}+}\right)_{\mathrm{i}}(\mathrm{OG})_{\mathrm{a}}\right]^{n+}$ clusters as a function of cluster charge for $\mathrm{Na}^{+}, \mathrm{Ca}^{2+}$, and $\mathrm{Yb}^{3+}$.

ison of Figure 3a with Table 1 shows that the minima appear at those a-values at which the (dominant) value of $i$ switches to the next higher integer, i.e., one more $\mathrm{Na}^{+}$ion is present in the clusters. For example, the third minimum is found at $\mathrm{a}=28$ and 29 , and for $\mathrm{a}=28$ and the nearest lower a-values, the clusters have no more than three $\mathrm{Na}^{+}$ions, whereas for $\mathrm{a}=29$ and the nearest higher a-values, they have four $\mathrm{Na}^{+}$ions. The minima disappear at higher $n$-values, as the extent of overlap increases with rising i-values. For example, clusters with $7 \mathrm{Na}^{+}$ions are observed within a relatively wide range of a-values, from 76 to 147 . This corresponds to a range of molecular masses from 22.4 to $43.1 \mathrm{kDa}$. This cluster pattern was followed to cluster with $10 \mathrm{Na}^{+}$ions and almost 200 OG molecules.

The $\mathrm{Na}^{+} / \mathrm{OG}$ cluster peak distributions were remarkably stable with changing experimental conditions. In particular, varying the concentration of OG or $\mathrm{Na}^{+}$by several orders of magnitude had no significant effect on the relative cluster abundance distributions.

\section{$\mathrm{Ca}^{2+} / \mathrm{OG}$ and $\mathrm{Yb}^{3+} / \mathrm{OG}$ Cluster Abundances}

To elucidate the remarkable abundance distribution of $\mathrm{Na}^{+} / \mathrm{OG}$ clusters, analogous experiments and analysis were performed for clusters in which the singly charged $\mathrm{Na}^{+}$was substituted with a doubly and with a triply charged metal ion. Results corresponding to those in Figure $3 \mathrm{a}$ for $\mathrm{Na}^{+} / \mathrm{OG}$ clusters are shown for $\mathrm{Ca}^{2+} / \mathrm{OG}$ in Figure $3 \mathrm{~b}$ and for $\mathrm{Yb}^{3+} / \mathrm{OG}$ clusters in Figure 4. In addition, the total abundances of $\mathrm{Ca}^{2+} / \mathrm{OG}$ and of $\mathrm{Yb}^{3+} / \mathrm{OG}$ clusters, as a function of i (i.e., number of metal ions in the clusters) are presented in Figure 2. The highest cluster charge states observed were $n=8$ for $\mathrm{Ca}^{2+}$ and $\mathrm{n}=9$ for $\mathrm{Yb}^{3+}$, respectively. This is about the same as for $\mathrm{Na}_{\mathrm{i}}^{+} \mathrm{OG}_{\mathrm{a}}$ clusters $(\mathrm{n}=10)$. The maximum number of doubly and triply charged ions present in the recorded clusters are correspondingly lower (4 and 3, respectively).

The total abundance of $\mathrm{Ca}_{\mathrm{i}}^{2+} \mathrm{OG}_{\mathrm{a}}$ clusters as a func- tion of $a$, is shown in Figure $3 b$. It is seen that the narrow minima for the $\mathrm{Na}_{\mathrm{i}}^{+} \mathrm{OG}_{\mathrm{a}}$ clusters between $\mathrm{i}=1$ and 2 and between $i=2$ and 3 , see Figure $3 a$, is replaced by a wide and flat minimum between $\mathrm{i}=1$ and 2 for $\mathrm{Ca}_{\mathrm{i}}^{2+} \mathrm{OG}_{\mathrm{a}}$ clusters as the total abundance of clusters is considerably lower in the range of $\mathrm{a}=16$ to 25 . A wider, but less pronounced minimum appears between $\mathrm{i}=2$ and 3. The gaps are even wider for the $\mathrm{Yb}_{\mathrm{i}}^{3+} \mathrm{OG}_{\mathrm{a}}$ clusters as depicted in Figure 4. Thus, no clusters that contained between $\mathrm{a}=35$ and 52 OG molecules could be detected, and this constitutes the gap between $\mathrm{i}=1$ and 2. Similarly, there is a narrower gap between $i=2$ and 3 , and no clusters with 110 to 116 OG molecules were observed.

It is seen in Figure $4 \mathrm{a}$ that additional types of clusters appear in the $\mathrm{Yb}^{3+} / \mathrm{OG}$ spectra for clusters with fewer than 17 OG molecules. Figure $4 \mathrm{~b}$ shows the normalized abundances of the clusters as a function of the number of OG molecules, expanded to clearly show this region.
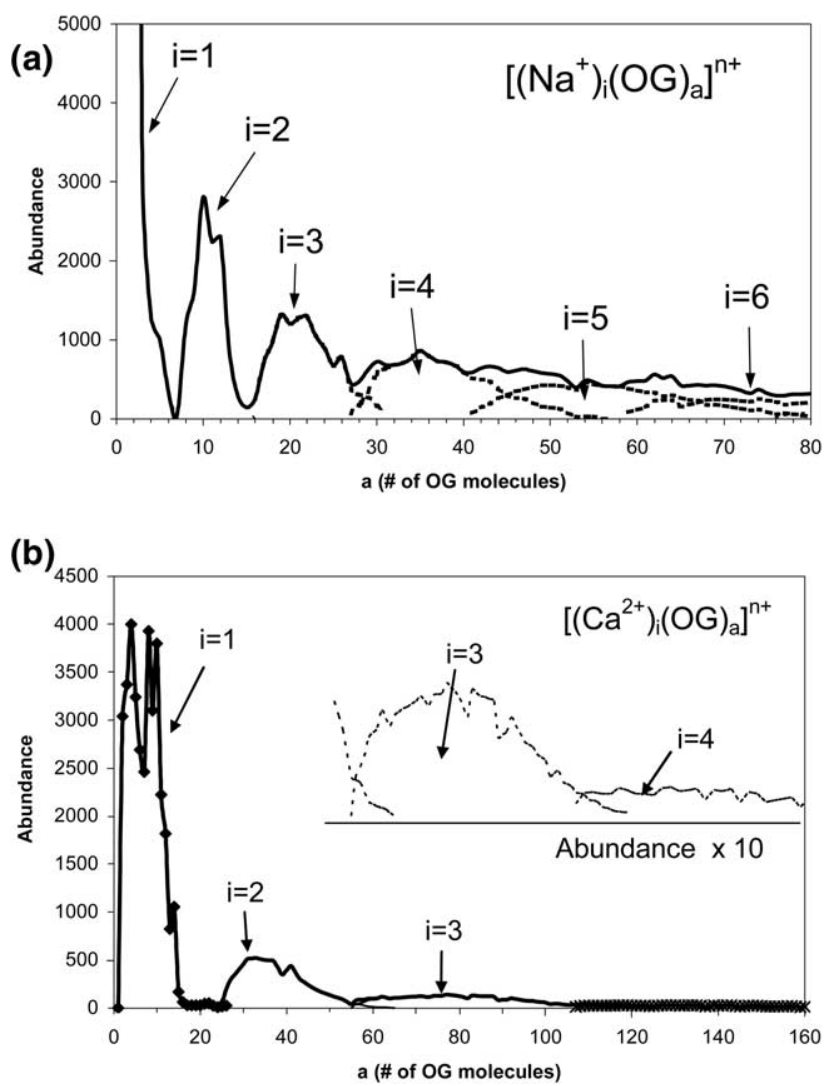

Figure 3. (a) Abundances of $\left[\mathrm{Na}_{\mathrm{i}}^{+}(\mathrm{OG})_{\mathrm{a}}\right]^{n+}$ clusters as a function of a. The abundance values for each row in Table 1 were summed up to obtain the total abundance of all clusters with a given number of OG molecules, $\mathrm{I}_{\mathrm{a}}=\Sigma \mathrm{I}_{\mathrm{i}, \mathrm{a}}$. Dashed lines show the contributions from the individual charge states. It is seen that the total cluster abundance oscillates strongly at lower a-values. (b) Abundances of $\left[\mathrm{Ca}_{\mathrm{i}}^{2+}(\mathrm{OG})_{\mathrm{a}}\right]^{n+}$ clusters expressed as a function of a. The abundances were summed over $\mathrm{i}$ to obtain the total abundance of all clusters with a given number of OG molecules, $\mathrm{I}_{\mathrm{a}}$ $=\Sigma I_{i, a}$. The inset shows the abundances for $\mathrm{i}=3$ and $\mathrm{i}=4$ clusters, multiplied by a factor of 10 . There is a significant gap in the total abundance for cluster with 16 to 25 OG molecules. 
(a)

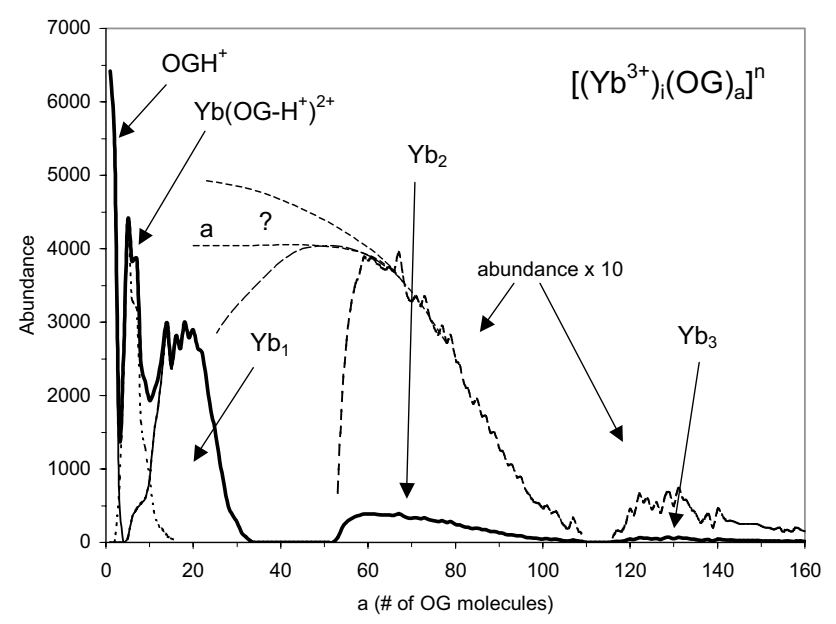

(b)

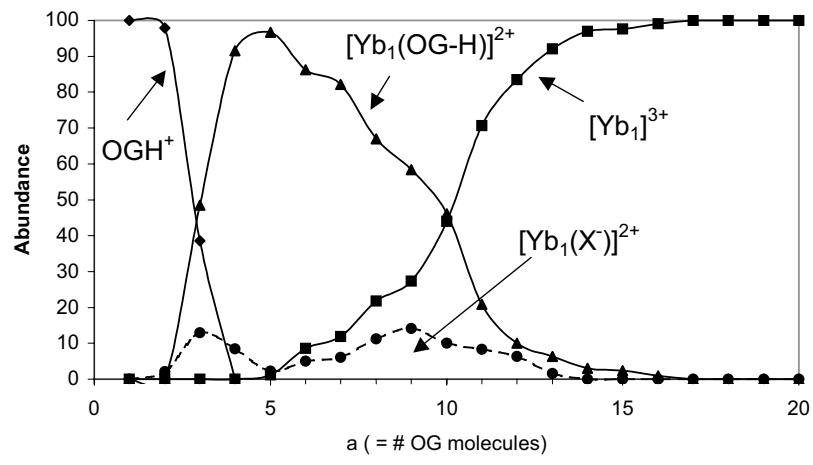

Figure 4. (a) Abundances of clusters in the $\mathrm{Yb}^{3+} / \mathrm{OG}$ system as

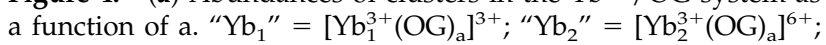
$" \mathrm{Yb}_{3}$ " $=\left[\mathrm{Yb}_{3}^{3+}(\mathrm{OG})_{\mathrm{a}}\right]^{\mathrm{a}+}$; "OGH ${ }^{+\prime}=\left(\mathrm{OGH}^{+}\right)(\mathrm{OG})_{\mathrm{a}-1}^{1+}$; and "Yb(OG $\left.-\mathrm{H}^{+}\right)^{2+\prime}=\left[\mathrm{Yb}_{1}^{3+}\left(\mathrm{OG}-\mathrm{H}^{+}\right)(\mathrm{OG})_{\mathrm{a}-1}\right]^{2+}$. The thick line shows the total cluster abundance. The dashed lines underneath this curve show the individual abundance contributions from "OGH ${ }^{+\prime}$, "Yb(OG-H $)^{2+"}$, and $\mathrm{Yb}_{1}$. Dashed lines show the abundances of the $\mathrm{Yb}_{2}$ and $\mathrm{Yb}_{3}$ clusters, multiplied with a factor of 10 . The dashed lines extrapolating the $\mathrm{Yb}_{2}$-abundance profile towards smaller a-values indicate different possible $\mathrm{Yb}_{2}$ "parent ion distributions", which includes those $\mathrm{Yb}_{2}$-clusters that dissociated to $\mathrm{Yb}_{1}$-clusters before MS detection. No clusters with 35 to 52 or with 110 to 116 OG molecules were detected. (b) Normalized abundances of clusters in the $\mathrm{Yb}^{3+} / \mathrm{OG}$ system as a function of a and for a from 1 to $20 . "\left[\mathrm{Yb}_{1}\left(\mathrm{X}^{-}\right)^{2+}\right]^{\prime}=\left[\mathrm{Yb}^{3+}\left(\mathrm{X}^{-}\right)(\mathrm{OG})_{\mathrm{a}}\right]^{2+}$.

Protonated OG clusters, $\left[\left(\mathrm{OGH}^{+}\right)(\mathrm{OG})_{\mathrm{a}-1}\right]^{1+}$, appear at a $=3$ and below, and deprotonated $\mathrm{Yb}^{3+} / \mathrm{OG}$ clusters, $\left[\mathrm{Yb}^{3+}(\mathrm{OG}-\mathrm{H})^{-}(\mathrm{OG})_{\mathrm{a}-1}\right]^{2+}$ are found in the range of $\mathrm{a}$ $=3$ to 16. A lower abundance series of peaks appear at mass corresponding to $\left[\mathrm{Yb}^{3+}\left(\mathrm{X}^{-}\right)(\mathrm{OG})_{\mathrm{a}-1}\right]^{2+}$. The species $\mathrm{X}$ has a mass of $185 \mathrm{Da}$, and remains unidentified.

\section{Discussion}

Clusters $\mathrm{Na}^{+} / \mathrm{OG}$ with a given number of OG molecules either have the same number or consecutive numbers of $\mathrm{Na}^{+}$ions (Figure $3 \mathrm{a}$ and Table 1). The overlap between consecutive cluster distributions increases with increasing cluster charge. Prominent abun- dance modulations were seen in Figure $3 a$, and for the multiply charged metal ions, these modulations became more pronounced. The $\mathrm{Yb}^{3+}$-containing clusters represent an extreme case in that no clusters are observed in a wide range of cluster sizes from 32 to 52 OG molecules. Any acceptable model of electrospray must account for these observations.

\section{The "Coulomb Explosion to Ion Evaporation" Transition Model}

Figure 5 is a graphical representation of the "Coulomb explosion to ion evaporation" transition model discussed in the Introduction. The droplet in the upper right corner represents a "last-generation" droplet, formed in the last step of a cascade of Rayleigh droplet disintegrations and containing $12 \mathrm{Na}^{+}$-ions. The arrows in the diagram follow the proposed evolution of this cluster. The mass of the cluster gradually decreases, as solvent molecules are lost. The dashed line represents the minimum mass at which ion evaporation will occur for a droplet with a given charge. As the droplet reaches this line, it will lose one charge with very little mass loss, effectively moving horizontally to the left (cursive in original text [20]). The horizontal line marked " $\mathrm{IE}_{12}$ " (ion evaporation from a cluster with $12 \mathrm{Na}^{+}$ions) represents this event. The process is repeated until the last volatile solvent molecule is lost. The mass of the involatile solid cluster (residue) will determine its charge. The authors points out that a prediction of this mechanism is that the respective ranges of (masses) of clusters having charges $z$ and

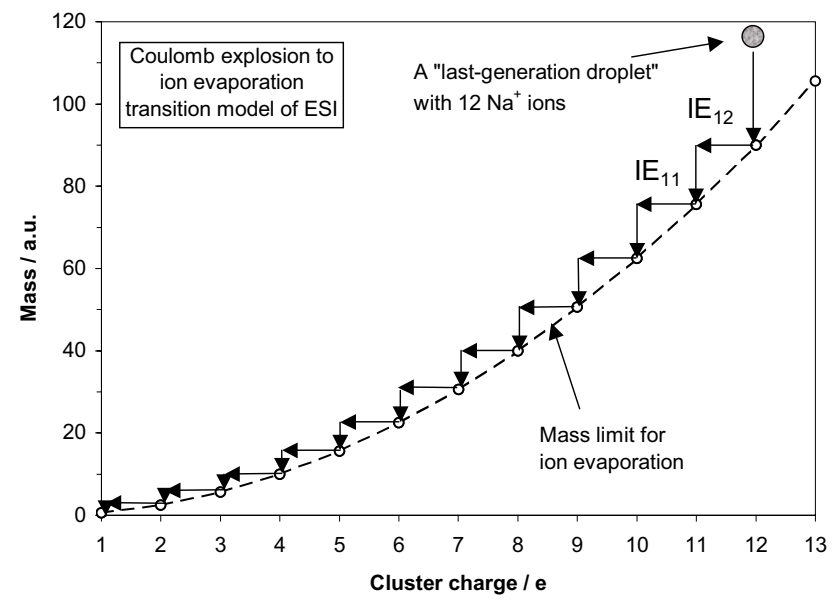

Figure 5. Graphical representation of the "Coulomb explosion to ion evaporation transition model" of electrospray. The dashed line shows the minimum mass of a cluster of given charge at which an ion evaporation event is considered to occur. The arrows show the evolution of a "last generation droplet" formed by a Rayleighinstability-driven disintegration of a larger charged droplet. In this example, the droplet has a charge of +12 . Line " $\mathrm{IE}_{12}$ " (ion evaporation from a cluster with $12 \mathrm{Na}^{+}$ions) shows the loss of a single ion from the droplet, without loss of solvent. The resulting daughter droplet loses water until a second ion evaporation event occurs at " $\mathrm{IE}_{11}$ ". The process is repeated until no volatile solvent remains. The mass of remaining involatile compounds will determine the charge state [20]. 
$z+1$ are contiguous to each other, without ever overlapping or leaving empty spaces in between.

A problem with the "Coulomb explosion to ion evaporation transition model" appears when trying to explain the observed cluster abundance patterns. In the work on organic salt clusters, $\left(\mathrm{A}^{+}\right)_{\mathrm{z}}\left(\mathrm{A}^{+} \mathrm{B}^{-}\right)_{n}$, it was found that clusters with $n=6$ and 7 are much less abundant than clusters with either lower ( 3 or 4 ) or higher $\mathrm{n}(8$ or 9$)$ [19]. The clusters are formed at the endpoint of the cascade in Figure 5, and the cascade ends when all volatile solvent molecules have evaporated. At that point all ion pairs that were present in the "last generation droplet" remain and together with the ions they constitute the final cluster. There is no reasonable explanation for why last generation droplets with 6 or 7 ion pairs should be less abundant than both those with fewer ion pairs and those with more ion pairs. Indeed, the model as described predicts that there should be no abundance modulations.

To explain the cluster abundance modulations, the "Coulomb explosion to ion evaporation transition model" would have to be amended. The reasonable assumption might be made that some ion pairs are removed in the ion evaporation events in Figure 5, especially when clusters have gone almost dry,

$$
\begin{array}{r}
\left(\mathrm{A}^{+}\right)_{\mathrm{i}}\left(\mathrm{A}^{+} \mathrm{B}^{-}\right)_{\mathrm{a}} \rightarrow\left(\mathrm{A}^{+}\right)_{\mathrm{i}-1}\left(\mathrm{~A}^{+} \mathrm{B}^{-}\right)_{\mathrm{a}-\mathrm{m}}+\left(\mathrm{A}^{+}\right)\left(\mathrm{A}^{+} \mathrm{B}^{-}\right)_{\mathrm{m}} \\
(\mathrm{m}=1-4)
\end{array}
$$

Such a process would be represented not by horizontal arrows but by sloping ones, in Figure 5. This would, indeed, result in minima in the abundance distribution. However, new issues appear. Consider the abundances of $\left[\left(\mathrm{Na}^{+}\right)_{\mathrm{i}}(\mathrm{OG})_{\mathrm{a}}\right]^{n+}$ clusters. Clusters with one $\mathrm{Na}^{+}$ion are rather small and have only 1 to 3 OG molecules, see Figure $3 \mathrm{a}$. One would therefore expect that the gaps between successive charge states would be quite narrow and well defined. Instead, the abundance gaps are wide and, in particular for the larger clusters, there is a very gradual change in abundances from one charge state to the next. A more serious issue is that with an increasing concentration of OG, there should be a shift towards larger clusters with more OG molecules in the "last generation" droplets and a strong tendency towards a bimodal distribution of cluster with one highabundance maximum for singly charged IEM-produced clusters and a second maximum for multiply charged CRM-produced clusters. None of these expected patterns are observed. In particular, there is a gradual and smooth decrease in cluster abundances with increasing numbers of OG molecules.

\section{Cluster Decomposition Reactions According to the Metal Ion/OG Data}

The most direct, fundamental, phenomenological description of ESI must center on how net charge, solutes, and solvent molecules of any disintegrating droplet distribute between daughter droplets as a function of the initial droplet conditions. To prematurely limit the analysis to a particular subset of such processes may well serve to obscure important phenomena that still need to be elucidated to reach the full potential of ESI. With this in mind, we will here examine the present data on metal ion/OG clusters for clues as to what reactions might have produced the observed clusters, rather than trying to fit existing models to the data.

\section{Symmetric $\mathrm{Yb}_{2}$-Cluster Divisions}

The distribution of $\mathrm{Yb}_{2}$-clusters in Figure $4 \mathrm{a}$ is seen to range from a low of 53 to a high of 110 OG molecules. (The notation " $\mathrm{Yb}_{\mathrm{i}}$ " here refers to all clusters that contain ${\mathrm{i} \mathrm{Yb}^{3+}}^{3}$ ions, irrespective of the number of OG molecules.) The distribution is markedly asymmetric with a sharp drop-off below $a=58$. The plausible interpretation is that clusters above the drop-off are stable and those below increasingly unstable. The $\mathrm{Yb}_{2}$ "parent cluster distribution" would include not only the detected clusters, but also the $\mathrm{Yb}_{2}$-clusters that dissociated into smaller clusters before detection. The dotted lines in Figure 4a indicate three reasonable, but hypothetical, "Y $\mathrm{b}_{2}$ parent distributions". While the extrapolation immediately below $\mathrm{a}=58$ is strongly suggested by the experimental curve, the behavior of the parent cluster curve becomes increasingly uncertain towards lower numbers of a.

The difference between the "parent" and "detected" $\mathrm{Yb}_{2}$ cluster curves represents $\mathrm{Yb}_{2}$ clusters that dissociated. The only reasonable products are two clusters with one $\mathrm{Yb}^{3+}$ each,

$$
\begin{aligned}
{\left[\left(\mathrm{Yb}^{3+}\right)_{2}(\mathrm{OG})_{\mathrm{a}} \mathrm{W}\right]^{6+} \rightarrow } & {\left[\left(\mathrm{Yb}^{3+}\right)_{1}(\mathrm{OG})_{\mathrm{a}-\mathrm{s}} \mathrm{W}\right]^{3+} } \\
+ & {\left[\left(\mathrm{Yb}^{3+}\right)_{1}(\mathrm{OG})_{s} \mathrm{~W}\right]^{3+} }
\end{aligned}
$$

The observation that the fall-off of the $\mathrm{Yb}_{2}$-clusters starts at 58 OG molecules and that the largest singly $\mathrm{Yb}_{1}$-clusters have $31 \mathrm{OG}$ molecules together show that the two daughter clusters have nearly equal size. Thus, a near-symmetric breakup of these clusters occurs.

The " $W$ " in eq 3 represents water that was left in the cluster at the time of dissociation. A critical issue is how much water was present. If a $\mathrm{Yb}_{2}$ cluster contains slightly less than 59 OG molecules, the presence of only a few water molecules should confer stability to the cluster and little or no water should have remained at the point of cluster dissociation. This is also consistent with the absence of strongly asymmetric dissociations, since, in the presence of many water molecules, the distribution of OG molecules would be expected to show a larger statistical variation, i.e., some $\mathrm{Yb}_{1}$-clusters would be expected to contain more than 31 OG molecules.

$\mathrm{Yb}_{2}$-clusters with considerably fewer than 59 OG molecules would have dissociated to $\mathrm{Yb}_{1}$-clusters while still containing significant numbers of water molecules. 
We will make the assumption that 10 water molecules stabilize a charged cluster as much as one OG molecule. A cluster that contained two $\mathrm{Yb}^{3+}$ ions and 40 OG molecules would then, in the absence of water, be 19 OG molecules short of being stable. This cluster would have dissociated into two single $\mathrm{Yb}^{3+}$ clusters when evaporation had reduced the number of water molecules to about 190 . In this case, the activation energy penalty for an asymmetric distribution of OG molecules is presumably small as it can be offset by an equally asymmetric distribution of the water molecules. Therefore, the two daughter clusters might contain maybe 13 to 27 OG molecules each, for a total of 40 . Such clusters are abundant in the mass spectra, and the data is clearly consistent also with large, water-containing clusters dissociating in a nearly symmetric manner. However, the data will not allow for large numbers of highly asymmetric $\mathrm{Yb}_{2}$ cluster dissociations, in which one of the $\mathrm{Yb}^{3+}$ ions would retain most of the OG molecules.

\section{Asymmetric $\mathrm{Yb}_{3}^{3+} / \mathrm{OG}$ Cluster Divisions}

The abundance profile for the $\mathrm{Yb}_{3}$-clusters in Figure 4a is similar to that for $\mathrm{Yb}_{2}$-clusters, with a relatively sharp cut-off at low mass and more gradual decrease towards high mass. The same arguments apply to show that eq 4 occurs.

$$
\begin{aligned}
{\left[\left(\mathrm{Yb}^{3+}\right)_{3}(\mathrm{OG})_{\mathrm{a}} \mathrm{W}\right]^{9+} \rightarrow } & {\left[\left(\mathrm{Yb}^{3+}\right)_{2}(\mathrm{OG})_{\mathrm{a}-\mathrm{s}} \mathrm{W}\right]^{6+} } \\
& +\left[\left(\mathrm{Yb}^{3+}\right)_{1}(\mathrm{OG})_{\mathrm{s}} \mathrm{W}\right]^{3+}
\end{aligned}
$$

The parent cluster, with about 120 OG molecules and a mass of about $35 \mathrm{kDa}$, must dissociate into one $\mathrm{Yb}_{2}$ cluster and one $\mathrm{Yb}_{1}$-cluster. Because no $\mathrm{Yb}_{1}$ clusters with more than 32 OG molecules are detected, the $\mathrm{Yb}_{2}$ cluster must retain at least three-fourth of the solvent (OG) molecules! This means that the mass of each cluster is approximately proportional to the square of the cluster charge. (This conclusion is supported by observations of dissociations of mixed $\mathrm{Na}^{+} / \mathrm{Ba}^{2+} / \mathrm{OG}$ clusters, to be reported elsewhere). We propose that in the dissociation of a multiply charged cluster,

$$
\mathrm{M}_{\mathrm{n}+\mathrm{m}}^{(\mathrm{p}+\mathrm{q})+} \rightarrow \mathrm{M}_{\mathrm{n}}^{\mathrm{p}+}+\mathrm{M}_{\mathrm{m}}^{\mathrm{q}+}
$$

the ratio of "solvent" molecules $\mathrm{M}$ in each cluster tend to be roughly equal to the square of the ratio of the charges,

$$
\mathrm{n} / \mathrm{m} \approx(\mathrm{p} / \mathrm{q})^{2}
$$

In the Rayleigh disintegration of large, charged droplets, it has been found that daughter droplets leave with $\sim 2 \%$ of the mass and $15 \%$ of the charge [7].

Parent droplet $\rightarrow$ Large droplet $(98 \%$ of mass,

$85 \%$ of charge) + daughter droplet(s)

( $2 \%$ of mass, $15 \%$ of charge)
Applying eq 6 to eq 7, one finds that $0.98 / 0.02=49$ and that $(0.85 / 0.15)^{2}=(5.7)^{2}=32$. It is noteworthy that eq 6 can be applied with some approximation also to the disintegration of $\mu \mathrm{m}$-sized droplets, although it has to be emphasized that more than one daughter droplets are generally produced in eq 7 . This observation underscores a fundamental similarity between the initial droplet disintegrations and final reactions that produce the observed ions.

\section{Dissociation of $Y b_{1}^{3+} / O G$ Clusters}

It follows from the discussion above that a fraction of the $\mathrm{Yb}_{1}$-clusters are formed by (near-symmetric) break-up of $\mathrm{Yb}_{2}$-clusters. Before discussing this issue, however, it is necessary to consider the origin of the singly and double charged ions in this system.

The $\mathrm{Yb}_{1}$ cluster abundance is seen to include $\left[\mathrm{OGH}^{+}(\mathrm{OG})_{\mathrm{a}-1}\right]^{1+}$ as well as $\left[\mathrm{Yb}^{3+}(\mathrm{OG}-\mathrm{H})^{-}(\mathrm{OG})_{\mathrm{a}-1}\right]^{2+}$ clusters. That these are formed by dissociation eq 8 is supported by the observation that the total abundances of the two product clusters are very similar.

$$
\begin{aligned}
{\left[\mathrm{Yb}^{3+}(\mathrm{OG})_{\mathrm{a}}\right]^{3+} \Rightarrow } & {\left[\mathrm{OGH}^{+}(\mathrm{OG})_{\mathrm{a} 1}\right]^{+} } \\
& +\left[\mathrm{Yb}^{3+}\left(\mathrm{OG}-\mathrm{H}^{+}\right)^{-}(\mathrm{OG})_{\mathrm{a} 2}\right]^{2+}
\end{aligned}
$$

Eq 8 is a concerted intra-cluster proton transfer and asymmetric cluster division reaction. Figure $4 \mathrm{~b}$ shows that $\mathrm{a}_{1}$ ranges from 1 to 3 and $\mathrm{a}_{2}$ from 3 to about 13 . We note that the ratio of OG molecules in the doubly to the singly charged cluster is $13 / 3$ or about $4\left(=2^{2}\right.$ as predicted by eq 6 .

\section{On the Sequence of Cluster Dissociations}

While clearly the last reactions to occur in the electrospray process are cluster divisions, such as $\mathrm{Yb}_{3} \rightarrow \mathrm{Yb}_{2}+$ $\mathrm{Yb}_{1}$ and $\mathrm{Yb}_{2} \rightarrow 2 \mathrm{Yb}_{1}$, it would be of great interest to trace the reaction scheme backwards. In particular, one would like to identify the precursor clusters to the $\mathrm{Yb}_{1}$ and $\mathrm{Yb}_{2}$. Such an analysis would provide deeper insights into the electrospray process.

With the reasonable assumption that observed $\left[\mathrm{OGH}^{+}(\mathrm{OG})_{\mathrm{a} 1}\right]^{+}$and $\left[\mathrm{Yb}^{3+}(\mathrm{OG}-\mathrm{H})^{-}(\mathrm{OG})_{\mathrm{a} 2}\right]^{2+}$ clusters are only produced by eq 8 , and that the cluster dissociations follow eq 6, the parent $\mathrm{Yb}_{1}$ clusters distribution can be derived. It is seen in Figure 6 that the calculated parent distribution forms a natural extension to the observed cluster distribution, and that the fall-off in abundance is shifted from about 10 to about 5 OG molecules.

The parent $\mathrm{Yb}_{1}$ clusters in Figure 6 must be formed from larger, more highly charged clusters or droplets, in particular from $\mathrm{Yb}_{2}$ clusters according to eq 3 and from $\mathrm{Yb}_{3}$-clusters according to eq 4 . The extensions of the $\mathrm{Yb}_{2}$ distribution towards lower OG numbers in Figure 4a indicates how many $\mathrm{Yb}_{2}$ clusters dissociated. Assuming that every such cluster dissociation is symmetric, the 


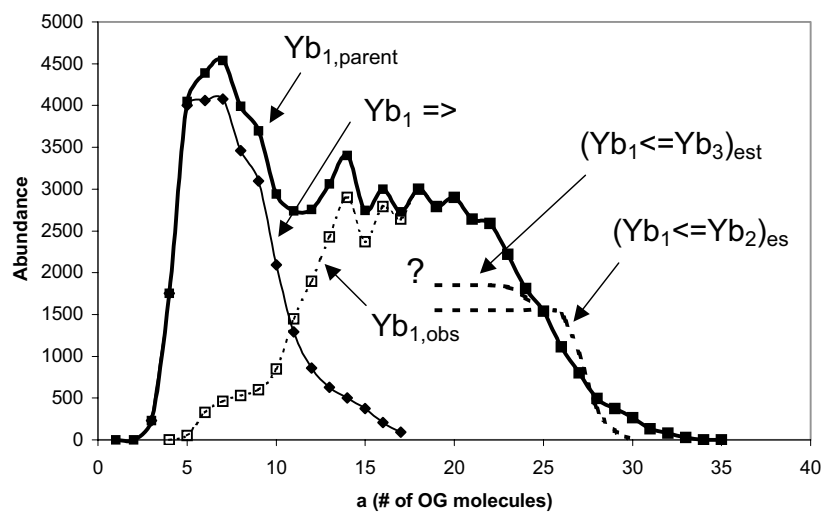

Figure 6. Analysis of $\mathrm{Yb}_{1}$ cluster distributions in the $\mathrm{Yb}^{3+} / \mathrm{OG}$

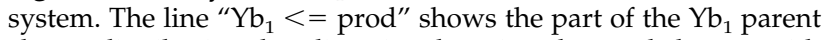
cluster distribution that dissociated to give observed clusters with one and two charges, according to eq 8 . This is added to the observed $\mathrm{Yb}_{1}$ distribution, "Y $\mathrm{b}_{1 \text {,obs }}$ ", to give the total $\mathrm{Yb}_{1}$ parent distribution, "Y $\mathrm{b}_{1 \text {,parent" }}$ " shown by the thick line. The two dashed lines show estimated contributions to the $\mathrm{Yb}_{1}$ parent distribution from the $\mathrm{Yb}_{2}$ parent distribution and the additional contribution from the $\mathrm{Yb}_{3}$ parent distributions, see text.

contribution of eq 3 to the overall parent $\mathrm{Yb}_{1}$ distribution is easily obtained. Using the line marked "a" in Figure $4 \mathrm{a}$, the result is shown by the line marked " $\mathrm{Yb}_{1}$ $<=\mathrm{Yb}_{2}$ " in Figure 6. Similarly, the line marked " $\mathrm{Yb}_{1}$ $<=\mathrm{Yb}_{3}$ " shows the contribution from eq 4. Judging from the results in Figure 6 most, if not all, $\mathrm{Yb}_{1}$ clusters with 20-30 OG molecules were formed from $\mathrm{Yb}_{2}$ and $\mathrm{Yb}_{3}$ clusters.

It is apparent that the fall-off towards higher mass in the distribution of $\mathrm{Yb}_{2}$ is more gradual than for the $\mathrm{Yb}_{1}$ distribution. When the analysis, illustrated in Figure 6 for $\mathrm{Yb}_{1}$ clusters, is repeated for the $\mathrm{Yb}_{2}$ cluster distribution, it is found that the $\mathrm{Yb}_{3} \rightarrow \mathrm{Yb}_{2}$ decomposition makes a relatively small contribution to the observed abundance of $\mathrm{Yb}_{2}$ clusters (results not shown). If correct, they would be formed primarily from larger clusters and droplets.

\section{Dissociations of $\left[\left(\mathrm{Na}^{+}\right)_{i}(\mathrm{OG})_{a}\right]^{n+}$ Clusters and the Role of Water}

The gaps in the $\mathrm{Yb}^{3+} / \mathrm{OG}$ cluster distribution allowed a detailed analysis of the final reactions in that system. In the $\mathrm{Na}^{+} / \mathrm{OG}$ cluster distributions, there are no such gaps, but only abundance minima; the number of charge states is larger; and the analysis it not as straightforward. The width of, and distance between, consecutive cluster regions become wider with increasing charge. The average number of OG molecules, $A(n)$, in detected clusters of charge $n$ is nearly proportional to the square of the charge as represented by eq 9 ,

$$
\mathrm{A}(\mathrm{n})=\mathrm{c} \times \mathrm{n}^{\mathrm{b}} ; \mathrm{b} \approx 1.85, \mathrm{c} \approx 3.0
$$

Both $\mathrm{Yb}^{3+} / \mathrm{OG}$ and $\mathrm{Ca}^{2+} / \mathrm{OG}$ clusters closely fit the same relation. This is not surprising as the Rayleigh eq
1 predicts the same functional dependence of mass on charge for droplets that are near their stability limits.

Figure $3 a$ shows that the decomposition of $\mathrm{Na}_{4}$ clusters, as an example, becomes important for $\mathrm{Na}_{4}$ clusters with 28 or fewer OG molecules. If such a cluster divides into two $\mathrm{Na}_{2}$ clusters, each would contain about 14 OG molecules and both would be stable. If, instead, the $\mathrm{Na}_{4}$ cluster divides into a $\mathrm{Na}_{3}$ and a $\mathrm{Na}_{1}$ cluster, these should, according to eq 6 , contain $\sim 27$ and 3 OG molecules, respectively, and would likewise be stable. The pattern that product clusters of nearly water-free parent clusters are stable holds for all dissociations in the accessible cluster range and is a direct corollary of eq 9. Thus, it might seem that any cluster dissociation sequence would quickly terminate. However, this view disregards the role of water molecules.

In Figure 7, $\left[\left(\mathrm{Na}^{+}\right)_{\mathrm{i}}(\mathrm{OG})_{\mathrm{a}} \mathrm{W}_{\mathrm{b}}\right]^{\mathrm{i}+}$ clusters are arranged according to their OG and water content. The diagonal lines represent the stability limits for clusters with the net charge indicated above each line. These were constructed using the stability limits in Figure 3a and the assumption that 10 water molecules are equivalent to one OG molecule. It is noteworthy that the stability limits for aqueous clusters obtained from the Rayleigh equation are close to the ones depicted in Figure 7 for zero OG molecules.

The diagram in Figure 7 can be used to illustrate possible cascades of dissociations of multiply charged, water- and OG-containing clusters. Point " $a$ " in the figure represents a cluster with $14 \mathrm{Na}^{+}$ions, $100 \mathrm{OG}$ molecules, and 2000 water molecules. The cluster has a mass of $65.5 \mathrm{kDa}$, a radius of about $3 \mathrm{~nm}$, is assumed stable, and would have been formed as a result of a preceding sequence of droplet and cluster dissociations. The cluster at "a" first loses water and reaches the limit

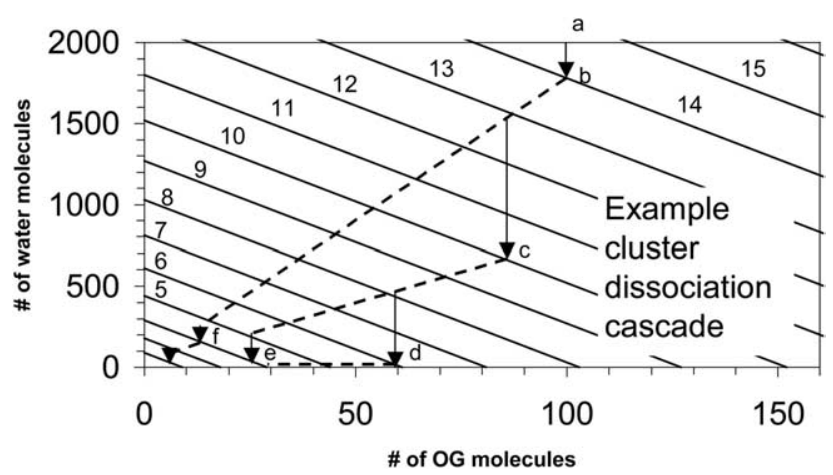

Figure 7. Illustration of stability limits and an example of a possible dissociation sequence for $\left[\left(\mathrm{Na}^{+}\right)_{\mathrm{i}}(\mathrm{OG})_{\mathrm{a}}\left(\mathrm{H}_{2} \mathrm{O}\right)_{\mathrm{b}}{ }^{\mathrm{i}+}\right.$ clusters. The diagonal lines represent stability limits for clusters with different numbers of $\mathrm{Na}^{+}$ions. The $\mathrm{Na}_{14} \mathrm{OG}_{100} \mathrm{~W}_{2000}$ cluster at point "a" loses water and is here assumed to dissociate at point "b" into a $\mathrm{Na}_{10}$ and a $\mathrm{Na}_{4}$ clusters. Each of the product clusters undergoes subsequent dissociations to produce a final distribution of clusters of different charge and size that is not unlike the observed distribution (eq 10). Many of the dissociation reactions for the smallest clusters cannot be shown but the ultimate products are given in the text. The stability limits for water-containing clusters represent reasonable guesses only. 
of stability for a $\mathrm{Na}_{14}$ cluster at point " $b$ ". In this example, the cluster is assumed to divide into a $\mathrm{Na}_{10}$ and a $\mathrm{Na}_{4}$ cluster. According to eq 6 , the $\mathrm{Na}_{10}$ cluster will retain about $86 \%$ of the solvent molecules (86 OG and 1530 water molecules). This cluster loses all but 660 water molecules to reach point " $\mathrm{c}$ ". At that point, it is considered to dissociate into a $\mathrm{Na}_{6}$ and a $\mathrm{Na}_{4}$ cluster. The dissociation sequence continues until all clusters have lost their water content. Such clusters are represented as points on the $\mathrm{x}$-axis in Figure 7 . In this particular hypothetical sequence, the following net reaction (eq 10) occurs:

$$
\begin{aligned}
& {\left[\mathrm{Na}_{14}^{+}(\mathrm{OG})_{100}\right]^{6+} \rightarrow\left[\mathrm{Na}^{+}(\mathrm{OG})_{1}\right]^{1+}+2\left[\mathrm{Na}^{+}(\mathrm{OG})_{2}\right]^{1+} } \\
&+\left[\mathrm{Na}^{+}(\mathrm{OG})_{3}\right]^{1+}+\left[\mathrm{Na}_{2}^{+}(\mathrm{OG})_{10}\right]^{2+}+\left[\mathrm{Na}_{3}^{+}(\mathrm{OG})_{24}\right]^{3+} \\
&+\left[\mathrm{Na}_{5}^{+}(\mathrm{OG})_{58}\right]^{5+}
\end{aligned}
$$

The clusters obtained in eq 10 and in other sequences, are all observed experimentally (see Figure 3a). The above demonstrates that the cluster dissociation model is able to explain the experimentally obtained cluster distributions.

\section{Additional Perspectives on Cluster Division Model of ESI}

One remaining aspect concerns the relative abundance of clusters with different numbers of $\mathrm{Na}^{+}$ions. The observed distribution, Figure 2, is of fundamental importance as it imposes restrictions on possible droplet and cluster dissociation cascades. It is not possible to fully address this issue here. Nonetheless, it should be noted that the extent to which clusters tend to disintegrate symmetrically or asymmetrically has a significant influence on the distribution. Thus, if one assumes that all cluster divisions result in loss of a $\mathrm{Na}_{1}$ cluster (i.e., ion evaporation), the products in the example given would be seven $\mathrm{Na}_{1}$ clusters and one $\mathrm{Na}_{7}$ cluster. Conversely, if it is assumed that all cluster divisions are symmetrical, the products are $6 \mathrm{Na}_{2}$ and $2 \mathrm{Na}_{1}$ clusters. Both distributions are qualitatively very different from the observed cluster distribution.

Our results demonstrate that the OG cluster distributions are determined by cluster dissociation dynamics and gas-phase stability considerations. However, the most convincing evidence that micelle formation does not affect the conclusions of our investigation is that nearly identical cluster distributions are observed for metal/sucrose clusters. Although there is no doubt that sucrose does not form micelles, OG was preferred for the present study because the largest $\mathrm{Na}^{+}$/sucrose clusters observed had only five charges. The results of studies using sucrose are the subject of a forthcoming publication.

It can be argued that because OG significantly lowers the surface tension of droplets and clusters, this may favor cluster dissociations at the expense of a putative ion evaporation process. The main counter argument is that results with sucrose are very similar to those obtained with OG.

\section{Relation of CDM to IEM and CRM}

In the past, discussions of ESI mechanisms have focused on the ion evaporation model (IEM) and the charged residue model (CRM). Here, a cluster division model (CDM) is proposed. The conceptual difference is very important. Neither the IEM nor the CRM are able to capture the essence of the cluster dissociation processes, as it is derived from the experimental data in the present work. In particular, IEM represents an extreme case of CDM, in which one of two daughter clusters has the smallest charge possible, i.e., one while the other retains the remaining charge. This is the case also for the CRM model when it is used to explain the maximum charge of globular proteins by a succession of ion evaporation events [9]. However, when the same subject is discussed in terms of Rayleigh droplet disintegrations [18], there is a similarity with CDM.

We argue that both the IEM and the CRM terms are too restrictive, and that they have often been used in a misleading manner. In future work to elucidate the processes that lead to observed ESI mass spectra, it will be necessary to consider a wide variety of cluster dissociation reactions, and it is unproductive to prematurely classify these into two simple categories.

\section{Conclusions}

The final stages of electrospray of aqueous solutions of involatile analytes and metal salts were shown to consist of symmetric and asymmetric cluster dissociation reactions. For the strongly solvated metal ions investigated in this study, the number of solvent molecules retained by each of two daughter clusters is roughly proportional to the square of the respective cluster charge. This cluster division model (CDM), proposed here, explains the observations of distinct cluster regions as well as the oscillations and gaps in the abundance distributions observed experimentally. There is no evidence of a transition from a Coulomb explosion phase to an ion evaporation phase. Instead, the cluster divisions are similar to Rayleigh droplet disintegrations.

The proposed model of electrospray of aqueous solutions of strongly solvated ions that has emerged from this work is simple and can be formulated as follows: After the initial production of charged droplets, a sequence of Rayleigh instabilities, with intervening periods of solvent evaporation, produces ever-smaller droplets. This disintegration process maintains its general character as it proceeds through the regime of multiply charged cluster dissociations to yield the finally observed singly and multiply charged ions. However, the degree to which the mass, charge, and solutes of the parent cluster become symmetrically or asymmetrically distributed between the product clusters 
does change and this aspect is essential to determine which ions are finally produced.

\section{Acknowledgments}

This work was supported by a Grant-in-Aid from the Japanese Ministry of Education, Science, and Culture, Special Coordination Funds for the Promotion of Science and Technology, no. 20403010.

\section{References}

1. Whitehouse, C. M.; Dreyer, R. N.; Yamashita, M.; Fenn, J. B. Electrospray interface for liquid chromatographs and mass spectrometers. Anal. Chem. 1985, 57, 675-679.

2. Yamashita, M.; Fenn, J. B. Negative-ion production with the electrospray ion-source. J. Phys. Chem. 1984, 88, 4671-4675.

3. Bruins, A. P.; Covey, T. R.; Henion, J. D. Ion spray interface for combined liquid chromatography/atmospheric pressure ionization mass spectrometry. Anal. Chem. 1987, 59, 2642-2646.

4. Rayleigh, L. On the equilibrium of liquid conducting masses charged with electricity. Phil. Mag. 1882, 14, 184-186.

5. Smith, J. N.; Flagan, R. C.; Beauchamp, J. L. Droplet evaporation and discharge dynamics in electrospray ionization. J. Phys. Chem. A 2002, 106, 9957-9967.

6. Grimm, R. L.; Beauchamp, J. L. Evaporation and discharge dynamics of highly charged droplets of heptane, octane, and p-xylene generated by electrospray ionization. Anal. Chem. 2002, 74, 6291-6297.

7. Gomez, A.; Tang, K. Q. Charge and fission of droplets in electrostatic sprays. Phys. Fluids 1994, 6, 404-414.

8. Kebarle, P.; Tang, L. From ions in solution to ions in the gas-phase-the mechanism of electrospray mass-spectrometry. Anal. Chem. 1993, 65, A972-A986.

9. Kebarle, P. A brief overview of the present status of the mechanisms involved in electrospray mass spectrometry. J. Mass Spectrom. 2000, 35, $804-817$.

10. Cech, N. B.; Enke, C. G. Practical implications of some recent studies in electrospray ionization fundamentals. Mass Spectrom. Rev. 2001, 20, 362-387.

11. Enke, C. G. A predictive model for matrix and analyte effects in electrospray ionization of singly-charged ionic analytes. Anal. Chem. $1997,69,4885-4893$.

12. Iribarne, J. V.; Thomson, B. A. Evaporation of small ions from charged droplets. J. Chem. Phys. 1976, 64, 2287-2294.

13. Thomson, B. A.; Iribarne, J. V. Field-induced ion evaporation from liquid surfaces at atmospheric-pressure. J. Chem. Phys. 1979, 71, 44514463.

14. Thomson, B. A.; Iribarne, J. V.; Dziedzic, P. J. Liquid ion evaporation mass-spectrometry mass-spectrometry for the detection of polar and labile molecules. Anal. Chem. 1982, 54, 2219-2224.

15. Dole, M.; Mack, L. L.; Hines, R. L.; Mobley, R. C.; Ferguson, L. P.; Alice, M. B. Molecular beams of macro-ions. J. Chem. Phys. 1968, 49, 2240-2249.

16. Kebarle, P.; Peschke, M. On the mechanisms by which the charged droplets produced by electrospray lead to gas phase ions. Anal. Chim. Acta 2000, 406, 11-35.

17. Gamero-Castano, M.; de la Mora, J. F. Kinetics of small ion evaporation from the charge and mass distribution of multiply charged clusters in electrosprays. J. Mass Spectrom. 2000, 35, 790-803.

18. de la Mora, J. F. Electrospray ionization of large multiply charged species proceeds via Dole's charged residue mechanism. Anal. Chim. Acta 2000, 406, 93-104.

19. Gamero-Castano, M.; de la Mora, J. F. Modulations in the abundance of salt clusters in electrosprays. Anal. Chem. 2000, 72, 1426-1429.

20. Gamero-Castano, M.; de la Mora, J. F. Mechanisms of electrospray ionization of singly and multiply charged salt clusters. Anal. Chim. Acta 2000, 406, 67-91.
21. Gamero-Castano, M.; de la Mora, J. F. Direct measurement of ion evaporation kinetics from electrified liquid surfaces. J. Chem. Phys. 2000, $113,815-832$.

22. Hiraoka, K. Laser spray: Electric field-assisted matrix-assisted laser desorption/ionization. J. Mass Spectrom. 2004, 39, 341-350.

23. Takamizawa, A.; Fujimaki, S.; Sunner, J.; Hiraoka, K. Denaturation of lysozyme and myoglobin in laser spray. J. Am. Soc. Mass Spectrom. 2005, 16, 860-868.

24. Fenn, J. B.; Mann, M.; Meng, C. K.; Wong, S. F.; Whitehouse, C. M. Electrospray ionization for mass spectrometry of large biomolecules. Science 1989, 246, 64-71.

25. Wong, S. F.; Meng, C. K.; Fenn, J. B. Multiple charging in electrospray ionization of poly(ethylene glycols). J. Phys. Chem. 1988, 92, 546-550.

26. Fenn, J. B.; Mann, M.; Meng, C. K.; Wong, S. F.; Whitehouse, C. M. Electrospray ionization-principles and practice. Mass Spectrom. Rev. 1990, 9, 37-70.

27. Meng, C. K.; Fenn, J. B. Formation of charged clusters during electrospray ionization of organic solute species. Org. Mass Spectrom. 1991, 26, pray ion

28. Zook, D. R.; Bruins, A. P. On cluster ions, ion transmission, and linear dynamic range limitations in electrospray (ion spray) mass spectrometry. Int. J. Mass Spectrom. Ion Processes 1997, 162, 129-147.

29. Zhou, S. L.; Hamburger, M. Formation of sodium cluster ions in electrospray mass spectrometry. Rapid Commun. Mass Spectrom. 1996, 10, 797-800.

30. Hop, C. E. C. A. Generation of high molecular weight cluster ions by electrospray ionization: Implications for mass calibration. J. Mass Spectrom. 1996, 31, 1314-1316.

31. Wang, G. D.; Cole, R. B. Solvation energy and gas-phase stability influences on alkali metal cluster ion formation in electrospray ionization mass spectrometry. Anal. Chem. 1998, 70, 873-881.

32. Charles, L.; Pepin, D.; Gonnet, F.; Tabet, F. C. Effects of liquid phase composition on salt cluster formation in positive ion mode electrospray mass spectrometry: Implications for clustering mechanism in electrospray. I. Am. Soc. Mass Spectrom. 2001, 12, 1077-1084.

33. Hao, C. Y.; March, R. E. Electrospray ionization tandem mass spectrometric study of salt cluster ions. Part 2. Salts of polyatomic acid groups and of multivalent metals. J. Mass Spectrom. 2001, 36, 509-521.

34. Hao, C. Y.; March, R. E.; Croley, T. R.; Smith, J. C.; Rafferty, S. P. Electrospray ionization tandem mass spectrometric study of salt cluster ions. Part 1. Investigations of alkali metal chloride and sodium salt cluster ions. J. Mass Spectrom. 2001, 36, 79-96.

35. Siuzdak, G.; Bothner, B. Gas-phase micelles. Angew. Chem. Int. Ed. 1995, 34, 2053-2055.

36. Nohara, D.; Ohkoshi, T.; Sakai, T. The possibility of the direct measurement of micelle weight by electrospray ionization mass spectrometry. Rapid Commun. Mass Spectrom. 1998, 12, 1933-1935.

37. Nohara, D.; Bitoh, M. Observation of micelle solution of decyltrimethylammonium bromide by electrospray ionization mass spectrometry. J. Mass Spectrom. 2000, 35, 1434-1437.

38. Cacace, F.; de Petris, G.; Giglio, E.; Punzo, F.; Troiani, A. Bile salt aggregates in the gas phase: An electrospray ionization mass spectrometric study. Chem. A Eur. J. 2002, 8, 1925-1933.

39. Rodriguez, M. A.; Yost, R. A. Interpretation of electrospray/ion trap mass spectra of bile acids and other surfactants. Rapid Commun. Mass Spectrom. 2000, 14, 1398-1403.

40. Nohara, D.; Kajiura, T.; Takeda, K. Determination of micelle mass by electrospray ionization mass spectrometry. J. Mass Spectrom. 2005, 40, 489-493.

41. Schalley, C. A. Supramolecular chemistry goes gas phase: The mass spectrometric examination of noncovalent interactions in host-guest chemistry and molecular recognition. Int. J. Mass Spectrom. 2000, 194, 11-39.

42. Dreisewerd, K. The desorption process in MALDI. Chem. Rev. 2003, 103, 395-425.

43. Karas, M.; Kruger, R. Ion formation in MALDI: The cluster ionization mechanism. Chem. Rev. 2003, 103, 427-439.

44. Sunner, J.; Morales, A.; Kebarle, P. Kinetic modeling of fast atom bombardment spectra of glycerol. Anal. Chem. 1988, 60,98-104.

45. Sunner, J.; Ikonomou, M. G.; Kebarle, P. SIMS spectra of alcohols and the phase explosion model of desorption ionization. Int. J. Mass Spectrom. Ion Processes 1988, 82, 221-237. 